\title{
Multiple Myeloma with Ovarian Plasmacytoma Mimicking Ovarian Carcinoma with Metastasis: A Case Report
}

\author{
Shivangi Agrawal, Ravinder Singh Gothwal, Vishnu Sharma, Sandeep Jain
}

SMS Medical College, Jaipur, India.

\begin{abstract}
Ovarian involvement in multiple myeloma is extremely rare. This paper reports a case of a 50-year-old female who presented with lower back and chest pain of one-month duration. Computed tomography imaging showed lytic lesions in the sternum, ribs, thoracic and lumbar vertebrae with a right adnexal mass. On pathological examination, plasmacytoma was confirmed from the adnexal mass. Bone marrow examination revealed plasma cell infiltration in bone marrow with positive light chain IgG lambda type in serum and raised microglobulin. She was finally diagnosed as a case of IgG lambda myeloma with ovarian plasmacytomas (RISS II).
\end{abstract}

Keywords: Multiple myeloma- extramedullary- Ovarian plasmacytoma

Asian Pac J Cancer Care, 6 (2), 227-230

\section{Introduction}

Multiple myeloma (MM) is typically characterized by neoplastic proliferation of plasma cells (PC) producing monoclonal paraproteins, as well as evidence of related end organ damage [1]. Each year over 32000 new cases are diagnosed in the United States, and almost 13000 patients die of the disease [2]. It is the most common plasma dyscrasia and accounts for $1.38 \%$ deaths in Indian subcontinent. Overall, 13\% of multiple myeloma patients have extramedullary disease (EMD): $7 \%$ at diagnosis and $6 \%$ during follow-up [3].

EMDs are unusual and typically occur as a solitary disease, most commonly in the upper respiratory tract, including the nasal cavities, paranasal sinuses, and nasopharynx and less frequently in kidney, breast, testis and ovary [4-6]. Extramedullary involvement has more aggressive features of myeloma including high LDH level, immunoblastic morphology, high tumor cell doubling index, and complex karyotypic features [7].

MM presenting as ovarian plasmacytoma is exceedingly rare. Only a few cases of ovarian plasmacytoma have been reported. Thus, experience in disease diagnosis and management is limited. Here, we describe a case of multiple myeloma with ovarian plasmacytoma with extensive bone lesions mimicking metastatic ovarian carcinoma.
Submission Date: 02/16/2021 Acceptance Date: 04/12/2021

\section{Case Presentation}

A 50-year-old postmenopausal female presented with complaints of backache, chest pain and fatigue from last 1 month. The pain was mainly in the lower back, dull aching, insidious onset, gradually progressive, non-radiating, not associated with trauma. The chest pain was dull aching, localized in the middle of chest, not associated with cough, dyspnea.

Physical examination revealed pallor with localized tenderness at sternum and dorsolumber region and no neurological deficit. Abdominal, respiartory and CVS examination was normal. CT scan chest showed expansile lytic lesions in sternum, posterior end of few left-sided lower ribs, multiple thoracic vertebrae and mild pericardial effusion. The patient was referred to SMS Hospital, Jaipur, India for further management.

Routine laboratory tests were done which showed $\mathrm{Hb}$ $6.7 \mathrm{gm} / \mathrm{dl}$, TLC 8600 , Platelet count of $4.38 \mathrm{lacs} / \mathrm{mm}^{3}$, normal AST, ALT and alkaline phosphatase, and KFT. To look for primary malignancy, contrast-enhanced CT scan abdomen (Figure 1.1) was done which revealed approximately $30 \times 31 \times 30 \mathrm{~mm}$ lobulated mass in right adnexa not involving the pelvic bone with lytic lesions in left lower ribs and L4 vertebrae. Serum marker CEA and CA-125 were within normal limit. USG guided core biopsy

Corresponding Author:

Dr. Ravinder Singh Gothwal

SMS Medical College, Jaipur, India.

Email: drravindragothwal@yahoo.com 
was taken from right adnexal mass. Histopathological examination of core biopsy demonstrated sheets of plasmacytoid cells. Immunohistochemistry was further performed which showed the cell to be diffusely positive for CD138 and negative for CD3, CD20, WT-1 and pan-cytokeratin favoring the diagnosis of plasmacytoma (Figure 1.2).

Further investigations were done to rule out multiple myeloma, laboratory tests showed ESR $105 \mathrm{~mm} / \mathrm{hr}$, serum proteins were $10 \mathrm{gm} / \mathrm{dl}$, Serum Albumin was $3.1 \mathrm{gm} / \mathrm{dl}$, Serum Globulin was $6.9 \mathrm{gm} / \mathrm{dl}$ and $\mathrm{A} / \mathrm{G}$ ratio was found to be 0.4 with normal serum calcium and LDH levels. $\mathrm{X}$-ray skull did not reveal any lytic lesions. Bone marrow examination showed normal $12 \%$ clonal plasma cells, suggestive of plasma cell pathology.

Further investigation revealed serum beta-2 microglobulin level of $2862 \mathrm{ng} / \mathrm{ml}$ and M spike of $4.7 \mathrm{~g}$ / $\mathrm{dl}$ on serum protein electrophoresis. Immunofixation electrophoresis demonstrated a monoclonal immunoglobulin G (IgG) lambda. Serum free light chain assay revealed elevated lambda light chain at $1348 \mathrm{mg} / \mathrm{l}$ and kappa free light chain were $5.62 \mathrm{mg} / \mathrm{l}$ with free lambda to kappa light chain ratio being 239.86 . Myeloma fluorescence in situ hybridization (FISH) panel identified deletion 13q14.3. Conventional $\mathrm{G}$ banding analysis revealed normal cytogenetics. She was finally diagnosed as a case of IgG Lambda myeloma with ovarian plasmacytoma (R ISS stage II). Treatment was started with Bortezomib, lenalidomide and dexamethasone (VRd). After six cycles of VRd regimen, computerized tomography imaging and serum electrophoresis showed very good partial response. (VGPR). Patient now has been counseled for autologous stem cell transplantation.

\section{Discussion}

In MM, bone marrow is infiltrated with aggregates of abnormal plasma cells and that leads to multifocal destructive lesions. The malignant plasma cells mainly affect the bone marrow, but may also spread to all the other important organs and tissues, resulting in extramedullary plasmacytoma. Extramedullary plasmacytoma commonly arises in the upper respiratory tract such as nasopharynx, paranasal sinuses, and other submucosal regions [5]. It can

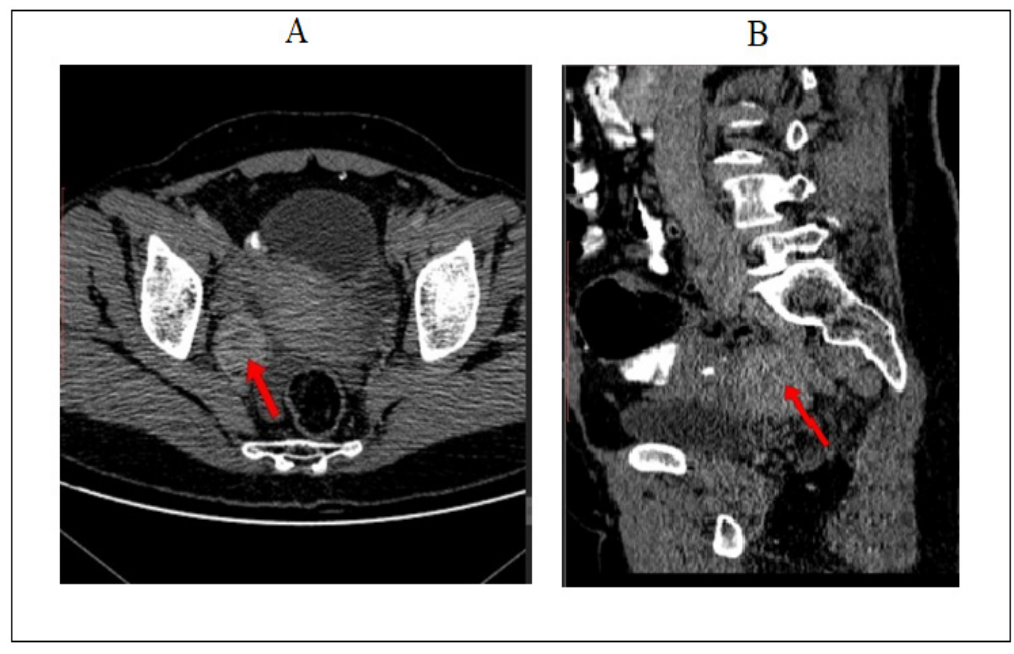

Figure 1.1. CECT Abdomen (A) Axial (B) Sagittal Section Showing Lobulated Mass in the Right Adnexa

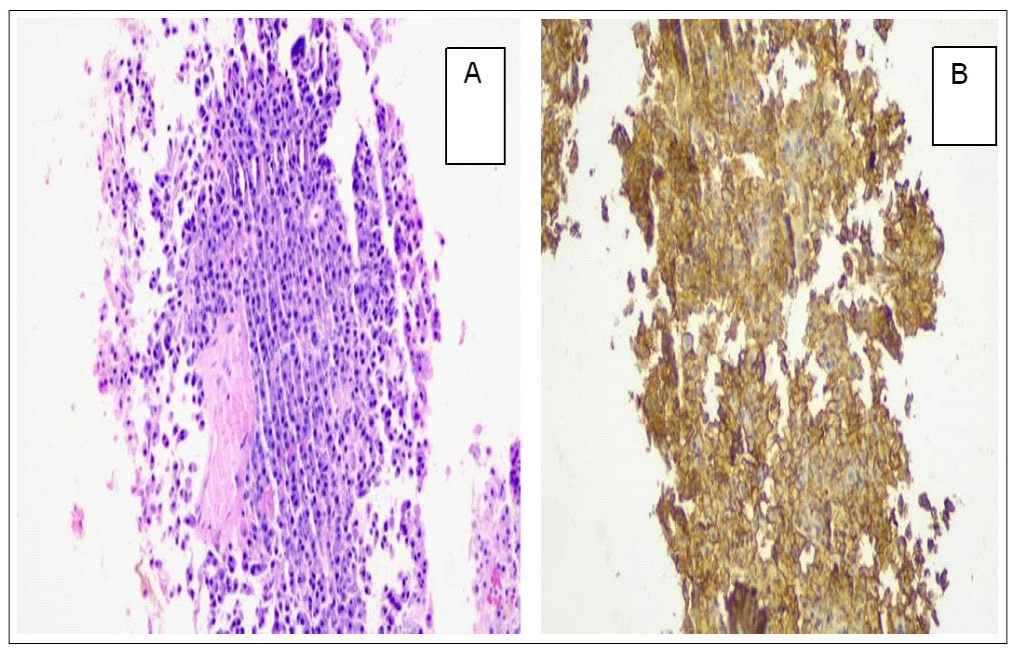

Figure 1.2. Immunohistochemistry (A) HE 10X, Show Sheets of Monotonous Plasma Cells. (B) CD138 10X, Tumor cells are immunopositive for CD138. 
also affect the stomach, intestine, lung, lymph node, skin, mediastinum and spleen, although the incidence is much less. It has seldom involved the female reproductive organs but ovarian plasmacytoma at presentation with MM is a rare entity [8]. Only a few cases have been described in the literature. Median age at diagnosis was 55 years. The age distribution is similar to other plasma cell disorders with predominance in females [9]. The patients usually have no specific symptom and the tumor usually reaches a significant size before becoming symptomatic. The ovary being a mobile structure in the pelvis usually causes no pain or mass symptom very late. The tumor reaches a significant size before being diagnosed; the median tumor size in the literature review was $10 \mathrm{~cm}$. We report this case for its rarity and several clinical, diagnostic dilemmas, and treatment related challenges.

In 2018, the European Society for Blood and Marrow Transplantation (EBMT) conducted a retrospective study in which spleen, ovaries, and testicles involvement in extramedullary disease was found to be $5.3 \%$ [10-11].

Multiple myeloma with EMD is known to have a highly aggressive course at presentation as well as in relapse setting. EMD at diagnosis was associated with lower progression free survival rate compared with multiple myeloma without EMD, regardless of treatment [12]. This patient had presented with lower backache which on various investigations came out to be a lobulated mass in ovary along with lytic lesions in multiple vertebrae.

Behrang kazeminez et.al. Reported a case of 48 years old women of multiple myeloma with bilateral ovarian involvement [13]. They reported neoplastic plasma cells in circulation, thus suspecting the hematogenous spread to be the possible route. The patient also had high serum levels of IgA and lambda light chain. In our case serum $\mathrm{M}$ protein spike along with increased monoclonal immunoglobulin G on serum electrophoresis was noted.

The lesion is histopathologically characterized by infiltrates of plasma cells of diverse maturity and by their monoclonal immunoglobulin products. Interestingly, in our patient, immunohistochemical stain of the ovarian biopsy revealed diffuse positivity for CD138, while the immunofixative electrophoresis of serum revealed monoclonal gammopathy of the IgG- $\lambda$ type.

Yu-Ping Zhong et.al. reported a similar case of 54 years old female patient, diagnosed as multiple myeloma, presented with complaint of intermittent abdominal pain which was reported solid adnexal mass in vaginal ultrasound and emergent laparotomy showed an enlarged right cystic ovary which was found to be plasmacytoma on histopathology [14].

MM with EMD usually requires systemic treatment with triplets (bortezomib, lenalidomide and dexamethasone) with radiation for local control in patients with plasmacytoma with almost equals results to that of surgical resection. But ovarian plasmacytoma pose a rare challenge to the radiation oncologist in that these tumors despite acquiring huge size are located in the pelvis.

Treatment of extramedullary disease is same as multiple myeloma but relapse rate is high. Chemotherapy is not usually needed in patients with isolated ovarian plasmacytoma without evidence of myeloma. The presented patient underwent chemotherapy with six cycles of bortezomib, lenalidomide and dexamethasone in view of MM with ovarian EMD and attained very good partial response (VGPR). Now patient has been counseled for autologous stem -cell transplantation.

Survival outcome in patients with MM with ovarian EMD was encouraging in the literature review with conventional therapy of MM with or without radiotherapy followed by autologous stem cell transplant. But analyzing outcomes from the case reports is usually difficult due to the inherent bias associated. But these patients may relapse early as the other site EMDs, so must be kept on regular and close follow-up.

\section{References}

1. Hasskarl J, Ihorst G, De Pasquale D, Schröttner P, Zerweck A, Wäsch R, Engelhardt M. Association of multiple myeloma with different neoplasms: systematic analysis in consecutive patients with myeloma. Leukemia \& Lymphoma. 2010 Nov 05;52(2):247-259. https://doi.org/10.3109/10428194. 2010.529207

2. Siegel RL, Miller KD, Jemal A. Cancer statistics, 2020. CA: A Cancer Journal for Clinicians. 2020 01;70(1):7-30. https:// doi.org/10.3322/caac. 21590

3. Siegel RL, Miller KD, Jemal A. Cancer statistics, 2019. CA: A Cancer Journal for Clinicians. 2019 01;69(1):7-34. https:// doi.org/10.3322/caac. 21551

4. Varettoni M, Corso A, Pica G, Mangiacavalli S, Pascutto C, Lazzarino M. Incidence, presenting features and outcome of extramedullary disease in multiple myeloma: a longitudinal study on 1003 consecutive patients. Annals of Oncology. 2010 02;21(2):325-330. https://doi.org/10.1093/annonc/ mdp329

5. Morariu I, Burns P, Roche P, Hone S. Triple manifestation of extramedullary plasmacytoma in the upper airway: an unusual clinical entity. The Journal of Laryngology \& Otology. 201106 17;125(9):970-972. https://doi. org/10.1017/s0022215111001046

6. Matsuda Y, Kato R, Miyao N, Sato S, Konishi Y, Kon S. A case of extramedullary plasmacytoma of testis converted to multiple myeloma . Hinyokika Kiyo. 2010;56:593-5.

7. Wang Y, Li F, Luo J, Li J, Xie L, Yang G. Testicular plasmacytoma: a case report and review of the literature. Chin Med J. 2008;121:956-8

8. Schor APT, Moraes MPT, Bisson FW, Bisson MAM, Luiz OMR, Bacchi CE. Primary Plasmacytoma of the Cervix in a 21-year-old Female Patient. International Journal of Gynecological Pathology. 2010 05;29(3):290-293. https:// doi.org/10.1097/pgp.0b013e3181c070b4

9. Schols SE, Tick LL. Recurrent extramedullary plasmacytoma in asymptomatic multiple myeloma: a case report. Journal of Medical Case Reports. 201502 19;9(1). https://doi. org/10.1186/s13256-014-0506-3

10. Weinstock M, Aljawai Y, Morgan EA, Laubach J, Gannon M, Roccaro AM, Varga C, Mitsiades CS, Paba-Prada C, Schlossman R, Munshi N, Anderson KC, Richardson PP, Weller E, Ghobrial IM. Incidence and clinical features of extramedullary multiple myeloma in patients who underwent stem cell transplantation. British Journal of Haematology. 201504 01;169(6):851-858. https://doi.org/10.1111/ bjh. 13383 
11. Gagelmann N, Eikema D, Iacobelli S, Koster L, Nahi H, Stoppa A, Masszi T, Caillot D, Lenhoff S, Udvardy M, Crawley C, Arcese W, Mariette C, Hunter A, Leleu X, Schipperus M, Delforge M, Pioltelli P, Snowden JA, ItäläRemes M, Musso M, van Biezen A, Garderet L, Kröger N. Impact of extramedullary disease in patients with newly diagnosed multiple myeloma undergoing autologous stem cell transplantation: a study from the Chronic Malignancies Working Party of the EBMT. Haematologica. 201802 01;103(5):890-897. https://doi.org/10.3324/ haematol.2017.178434

12. Usmani SZ, Rodriguez-Otero P, Bhutani M, Mateos $\mathrm{M}$, Miguel JS. Defining and treating high-risk multiple myeloma. Leukemia. 201508 12;29(11):2119-2125. https:// doi.org/10.1038/leu.2015.209

13. Kazeminezhad B, Zare-mirzaie A, Mirafsharieh A, Soleimantabar H, Zahedifard S. Bilateral ovarian involvement: A rare presentation of disseminated multiple myeloma. Journal of Obstetrics and Gynaecology Research. 201207 29;39(1):446-449. https://doi.org/10.1111/j.14470756.2012.01972.x

14. Zhong Y, Zhang J, Huang X. Multiple myeloma with rupture of ovarian plasmacytoma. Chin Med J. 2012;125(16):294850.

\section{$0 \otimes$}

This work is licensed under a Creative Commons AttributionNon Commercial 4.0 International License. 